\title{
Formal Institutional Factors Influencing the Entrepreneurial Intent in Quindío (Colombia)
}

\author{
Edwin Tarapuez ${ }^{1}$, Beatriz Guzmán-Díaz ${ }^{2}$, Ramiro Parra-Hernández ${ }^{3}$ \\ ${ }^{1}$ Senior Professor, Program of Public Accounting, Faculty of Economic, Administrative and Accounting Sciences, \\ Universidad del Quindio, Armenia,Colombia.e-mail: eitarapuez@uniquindio.edu.co \\ ${ }^{2}$ Tenured Faculty Member, Program of Business Administration, Faculty of Economic, Administrative and Accounting \\ Sciences, Universidad del Quindio,Armenia,Colombia.e-mail: beguzman@uniquindio.edu.co \\ ${ }^{3}$ Tenured Faculty Member, Program of Business Administration, Faculty of Economic, Administrative and Accounting \\ Sciences, Universidad del Quindio, Armenia, Colombia.e-mail: rparra@uniquindio.edu.co
}

\begin{abstract}
The objective of this research is to analyze the formal institutional framework that influences the intention to create companies in the department of Quindío (Colombia). The study is descriptive and uses the transversal-nature non-experimental methodology. According to the structure of the project and the type of information collected, the research is mixed natured. This work involves obtaining information from two groups of sources that were chosen by convenience: fourteen public and private institutions connected to entrepreneurship in the region, to which a semi-structured questionnaire was applied, and four experts on entrepreneurship on whom an unstructured interview was applied. The research uses the theoretical institutional framework proposed by Douglas North as regards formal institutions. The findings conclude that the works by the different formal entities that support entrepreneurship in Quindío is disperse and that they are not articulated in a specialized and collaborative work scheme that fosters the achievement of a common goal to generate a positive impact of greater magnitude at the departmental level.
\end{abstract}

KEYWORDS: Douglas North, entrepreneurial intent, entrepreneurship, institutionalism

\section{Introduction}

Entrepreneurship has positioned itself as an important driver of the economies of countries by promoting, among other factors, innovation, competition and employment (Nenzhelele, 2014). Therefore, entrepreneurship and business creation have been regarded as key factors for regional development, possibly because the results of national and international efforts to stimulate entrepreneurship in less-advanced economies have often been disappointing (García, García and Diaz, 2018).

In this sense, in recent years, research on entrepreneurship and regional studies seem to be more interrelated, while research on regional entrepreneurship has become more popular (Carvalho, 2018), as there are apparently particular aspects associated with the territory that influence the creation of companies. At the same time, the interaction between entrepreneurship and institutions is a determining factor for economic development (Tao 2016; Elert and Henrekson 2017). In this sense, entrepreneurs have a fundamental influence capable of changing institutions (Kuchar 2016), whether they respect, attempt to alter or evade them (Elert and Henrekson 2017), while the institutional environment has a positive and significant impact on the entrepreneurial intent (EI) of individuals (Mouselli and Khalifa 2017).

Quindío is one of the 32 departments of Colombia and is the second smallest in the country with only $1,845 \mathrm{~km}^{2}$, it has a population of about 570,000 inhabitants and is located in the mid-west of the nation in the Andean region. Its economy is based on the sectors of trade and services, and agriculture, hunting and fishing. It is important to note that Quindío belongs to the area called the Coffee Growing Axis, which is the region that has traditionally produced coffee in Colombia. The area is also characterized by the wide range of tourist accommodation on coffee farms and its theme parks that revolve around the agricultural culture of the area.

However, despite the relative improvement in employment rates experienced by Colombia until 2018, the rate of unemployment in the region has not been able to drop from two digits. Since this year, according to the National Administrative Department of Statistics (DANE), unemployment has risen again at the national and regional levels. The unemployment rate in Colombia in the November 2018 - January 2019 mobile quarter was 10.4\%, representing an 
increase of $0.8 \%$ compared to the same period of the previous year; while the city of Armenia (the capital of Quindío) ranked fourth in unemployment in the country with a rate of $16 \%$ in the same period, which represents an increase of $1.4 \%$ compared to the same period of the previous year.

According to the Chamber of Commerce of Armenia and Quindío (2018), the number of companies incorporated increased from 12,826 in 2011 to 19,205 in 2017, which represents an increase in the business density ratio of 28 companies per thousand people in 2011 to almost 34 in 2017. It can also be observed that the number of new companies created has increased year after year, to the point that 5,475 (15 companies per day) were created in 2017 , of which $88 \%$ belong to natural persons and $12 \%$ to legal entities. Despite the above, the volume of assets reported by startups decreased from $\$ 55,172$ billion to $\$ 47,238$ billion.

On the other hand, between 2015 and 2017 around 2,200 companies closed down per year of which $66 \%$ shut down operations when they had been operating for three years or less. This report also shows that $96 \%$ of the total number of companies registered in 2017 correspond to microenterprises, that is, productive units with 10 employees at most. As can be seen, the business structure of the region is characterized by focusing on the tertiary sector, with the majority participation by smaller companies and an increase in the density of productive units.

The core objective of this paper is to analyze the formal institutional framework that influences EI in the department of Quindío (Colombia). This document is divided into six components, to wit, introduction, theoretical framework, methodology, results, conclusions and bibliographic references.

\section{Theoretical framework}

Regarding theoretical references, it should be mentioned that an increasing number of research has used the institutional theoretical framework since the 90s, although EI gained real interest as a field of research about two decades ago, time during which it has grown to the point that it has formed a heterogeneous area of study (Liñán and Fayolle 2015).

According to Nenzhelele (2014), entrepreneurship is a process and EI is its first step. No business behavior occurs by accident, as they are intentionally planned, so EI is the best predictor of business behavior. For Bird (1988), the intention corresponds to a process that is required before carrying out a certain action, that is, EI can be assumed as an a priori step to the action of creating a business. Thompson (2009), meanwhile, assumes EI as a self-recognized conviction by individuals who intend to create new businesses and who consciously plan to do so at some point in their future life. Fini, Grimaldi, Marzzochi, and Sobrero (2009), define EI as a personal projection of future actions and goals to be implemented to create one's own business.

In the study of the business process, research has revealed the importance of institutions in the development of the system because, according to Tao (2016), the economy deals with them. In this regard, there are two basic currents of institutional economic thinking, namely the Original Institutional Economics based on the tradition of Veblen, Ayres, Commons and Mitchell, and the New Institutional Economics, known as the North-Williamson School, which considers companies to be one of the most important institutions in the modern world (Parada 2003). According to Urbano, Díaz and Hernández (2007), North is among the authors of the new institutional economics, whose proposal provides an adequate theoretical reference to explain the aspects that influence the creation of companies.

North's main contribution (1993a) is his input to the studying of institutions, institutional change and their implications for economic development. In this way, institutions create the limitations established by the human being that shape the interaction between individuals and promote incentives for different exchanges. Subsequently, North (1993a,b) defines institutions as society's rules of the game, that is, they constitute the limitations devised by men that promote human interaction and, at the same time, structure incentives for human exchange of various kinds (political, social or economic).

By mentioning that these are the rules of the game, he does it literally, as he compares what happens in society with what happens during a sporting encounter, where there are written formal 
rules and "generally unwritten codes of conduct that underlie and complement formal rules, such as not deliberately hurting a key player of the opposing team" (North, 1993a, 14). North equates institutions with the rules of the game, and players with organizations and their entrepreneurs. In short, he assumes that "The purpose of the rules [of institutions that is] is to define how the game will play out” (p.15).

According to North (1993a, 14), "Institutions reduce uncertainty because they provide a structure to daily life." In this regard, he mentions a series of everyday situations in which institutions serve to guide actions between individuals. He mentions cases as disparate as burying the dead or setting up a business, where people know how to do it or can easily find out. He also clarifies that these institutions change from country to country. According to Tao (2016), institutions are broadly defined as lasting systems of established and incorporated social rules that structure social interactions. Language, money, law, weight and measuring systems, vehicle traffic rules, table manners, companies and other organizations are all institutions.

For North (1993a), it is important to clarify that there are two types of institutions, formal and informal ones. He points out that both are human creations and that therefore the initial analysis must be based on the individual, since "Institutions arise from individual behavior, through the interaction between individuals" (Parada 2003, 95). Formal institutions, thence, refer to those that can be created, such as the Political Constitutions of States, while informal ones correspond to what he calls common law, which corresponds to uses and customs, which evolve over time. North argues that informal institutions are more difficult to change than formal ones and carry a greater weight in determining human behavior (North 1981, 1993a).

In this sense, Chang (2006) argues that some formal institutions work very well in developed countries and do so because they are backed by a set of tacit informal institutions that are not easily observed. North $(2000,147)$ even mentions that "The imposition of a set of formal rules on an existing culture whose informal restrictions are not consistent with the new set of formal rules is the recipe for political and economic failure."

On the other hand, North (1993a) also states that organizations or bodies "are groups of individuals tied by some common identity towards certain objectives" (p. 15) and notes that the way of evolution and its survival depend on the institutional framework, while organizations are agents of institutional change. Organizations, according to North, are stable but in permanent change and can be of several kinds, such as political, economic, social and educational.

Thus, Jakšić and Jakšić (2018) assume that the key role of institutions is to ensure stability and continuity. Aside from the independence and responsibility of the institutions, what is needed is a sufficient level of inclusion. The introduction of the principles of independence, responsibility and inclusion is essential for the emergence and performance of all institutions. In this sense, Eesley, Roberts, Tian and Yang (2014) argue that flexible institutions foster entrepreneurship by allowing the development of individual choices. In economics, a shift from rigid to more flexible institutional rules is found to increase entrepreneurship

\section{Methodology}

The research is descriptive and uses the transversal-nature non-experimental methodology. According to the structure of the project and the type of information collected, the research is mixed-natured. Information was obtained from two groups of sources: institutions connected to entrepreneurship in the region and experts on entrepreneurship. To collect information from the first group, the form validated by Díaz (2003) was adapted, while the experts on entrepreneurship were approached through an unstructured interview.

For the analysis of the formal institutional aspects, 14 public and private entities, which have services to support entrepreneurship in the Quindío, were: the Chamber of Commerce of Armenia and Quindío, EAM University Institution, Bancolombia, Colombia's Hotel and Tourism Association (Cotelco), National Federation of Traders - Fenalco -, Act Famiempresas (microcredits), Remington University Corporation, Bank Woman World, Social Prosperity (governmental entity that assists vulnerable groups in their social and economic reintegration), 
National Learning Service (SENA Quindío), University of Quindío, Governorate of Quindío and the Mayors' Offices of Armenia and Calarcá. The collection of information was conducted through semi-structured interviews during the first half of 2018.

On the other hand, four experts on entrepreneurship were chosen by convenience, different from those chosen in the sample of institutions. The four experts were approached through informal interviews, two are men and two are women, who have extensive experience in the regional business field.

\section{Results}

\section{Overview of the institutions}

In the case of Colombia, the central administration of the country functions as a roof that houses institutions to support entrepreneurship, develop policies and programs at the national level, several of them are based in the department of Quindío, a situation that allows them to interact with local and regional entities to support the creation of companies. These institutions make up the formal framework to support the creation of businesses, within which the entities that make part of the Regional Entrepreneurship Network are also highlighted, whose incorporation is regulated by article 6 of Act 1014 (Congress of the Republic of Colombia, 2006) (Figure 1).

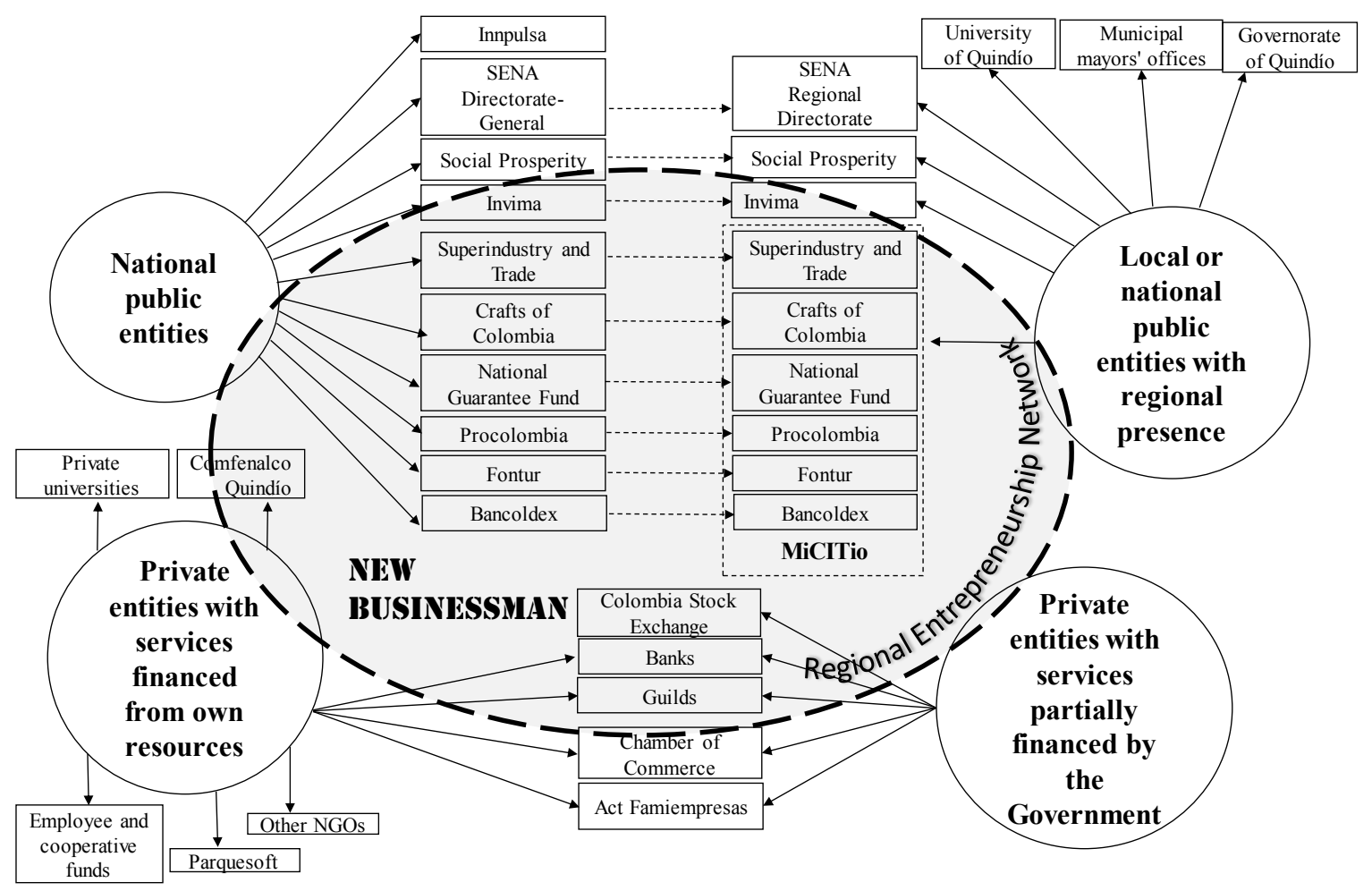

Figure 1. The formal institutional framework to support entrepreneurship in Quindío

Regarding the budget allocated to entrepreneurial activities, 6 of the 14 entities surveyed are not clear regarding the number of resources assigned to this activity. As for the institutional objectives, only three (SENA, University of Quindío and Chamber of Commerce) intend to specifically generate a culture of entrepreneurship in the department.

Regarding dependence on other public and/or private institutions only four mention that they depend on other entities (the Governorate, the Mayor's Office of Armenia, the Remington University Corporation and Cotelco), however, eleven organizations say they collaborate with other institutions. The SENA is the entity most connected with the organizations interviewed. 


\section{Measures to support the creation of new businesses}

Nine institutions have economic measures to support entrepreneurship, three of them do so through venture capital, four provide loans and two provide subsidies. On the other hand, with regard to non-economic strategies, 13 entities offer information, guidance, advice and support, 12 provide training, 11 follow-ups and 6 provide incubation and business development services.

Concerning the target population, the affiliated entities were noted to not have a specific group to which they target their programs. Despite the fact that young people, women and vulnerable population are the three groups that receive the most support measures from these institutions, it is evident that the majority of organizations provide support to different groups of the population that are interested in creating businesses (unemployed, pensioners, students, graduates, immigrants, entrepreneurs and the citizens in general). Public entities such as the SENA, the Governorate and the Mayor's Office serve the largest number of population groups in the department. Only Fenalco does not focus its measures on a delimited population.

Regarding the perception of institutions as to whether their support services and programmes are known to potential entrepreneurs, nine institutions have a positive perception, while the other five believe that they are newly created entities or that their programmes were recently designed. Specifically, Social Prosperity assumes that potential entrepreneurs do not know support services because these types of programs are regularly adjusted or because there is no dissemination.

Regarding the use of institutional support services and programs by potential entrepreneurs, 11 of the 14 entities studied assume that these are widely used. The reasons that are argued relate to the scarcity of services offered by other entities, the wide demand by potential entrepreneurs, an adequate approach to the services provided and the demand for stakeholders to stay in some programs to access other services. Six institutions believe that business support measures should be undertaken differently, for they believe that entities could agree on differential schedules so as not to cross with the same programs as other organizations; more funding sources are needed, as well as a more personalized approach, and being closer to the different groups of the population.

About the main sources of funding for institutions supporting business creation, public organizations or national government support programs support six entities. The remaining eight entities use their own resources or other companies to finance entrepreneurship supporting activities. Furthermore, it is emphasized that the governorate and the mayors' offices support each other in the development of community projects. None of the entities studied mentioned international support as a source of funding for business supporting activities. Figure 2 shows the sources of funding for institutional support measures and the importance of contributions from the national government, institutions' own resources and contributions from other companies. According to the information collected, the contributions by municipal and departmental governments are the least representative.

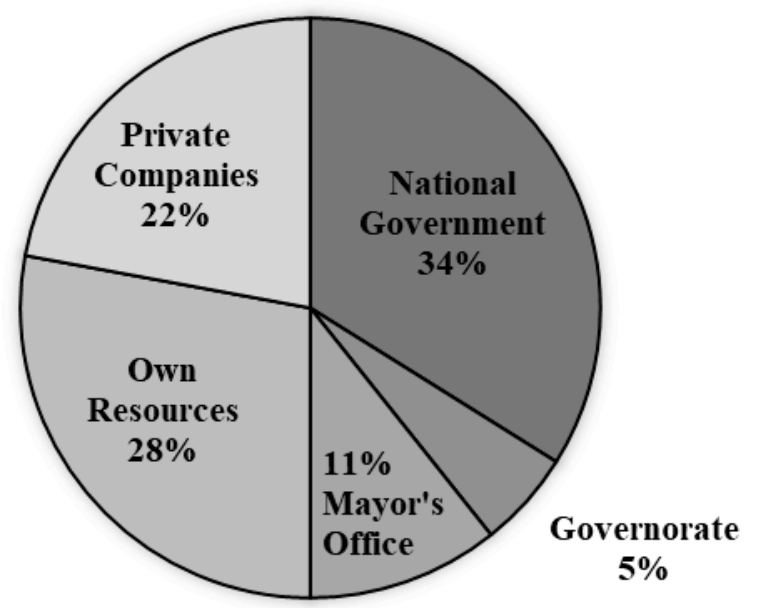

Figure 2. Sources of funding for institutional support measures 
With regards to the conditioning of the source of funding, eight institutions consider that it does not limit the type of support for entrepreneurship, while six entities presume that it is conditioned, especially by five of them. Some constraints relate to the type of target population, credit experience and behavior, and the consistency of projects with expected results.

\section{Assessment of entrepreneurship support measures}

The interviews provide valuable information about the recognition of other institutions that support entrepreneurship in Quindío. A special highlight is the SENA $(26 \%$ of the total number of responses), followed by the Governorate (15\%), the Chamber of Commerce and Act Famiempresas (14\% each); the Mayors' Offices (12\%); the aforementioned banks (7\%), universities (5\%) and others, including Parquesoft, Colciencias and cooperatives, obtained a total of $7 \%$ of the responses (figure 3).

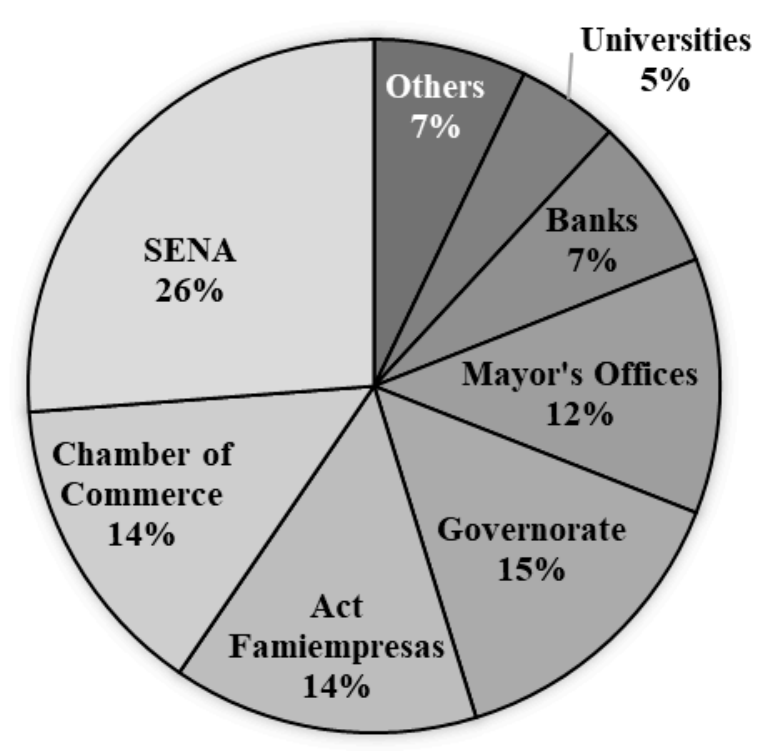

Figure 3. Identification of institutions that support entrepreneurship most (\%)

On the other hand, the interviewees consider that the institutions they represent have a notorious commitment to promoting entrepreneurship in the region, however, representatives of the entities interviewed argue that the support programs are insufficient and incipient and that they do not yet have the necessary resources to provide greater support to entrepreneurs.

Regarding the knowledge of entrepreneurs about the measures that support the creation of businesses in the department, seven of the entities interviewed assume that entrepreneurs know the institutional offer of support means; the other seven entities believe that there is a need for greater dissemination so that those interested in creating a company know the offer of programs to support entrepreneurship. They also mention that they work with insufficient resources and that entrepreneurs are unaware of other sources of funding.

\section{Conclusions}

In general, there are a significant number of entities that support entrepreneurship from different scopes, however, their work is disperse and they are not articulated into a collaborative work scheme that pursues a common objective explicitly to generate a positive impact of greater magnitude in the creation of companies at the departmental level.

On the other hand, formal institutions promoting entrepreneurship in Quindío (except one of those interviewed) do not have a specific target population on which to focus their programs and projects. In this sense, support is provided in a generic way to all individuals who require support in the creation of their own business, regardless of whether it materializes or not. Despite the above, 
the institutions analyzed assume that their programs are known among the population with EI and that the people concerned use them.

Although there is an interrelationship between institutions to support entrepreneurship in Quindío, the entities involved in the creation of companies are unaware of the dependence and collaboration level with other agencies. Despite this, SENA leads as the entity that brings together much of the efforts to promote entrepreneurship and the creation of new companies in the department.

On the other hand, it is seen that the entities linked to support the creation of companies show duplicity in their functions and strategies to support entrepreneurs, which implies oversupply of services in some fields such as training and deficit in others such as marketing and availability of seed capital. This situation implies that a greater degree of specialization by each entity could be sought in some of the components of the value chain of business creation and the development of institutional competencies in areas where support is still lacking.

Funding for entrepreneurship development activities in Quindío is provided especially through local and national resources, although there appears to be a lack of budgetary commitment on the part of the mayor's office of Armenia and the Governorate of Quindio, however, the latter entity enjoys recognition among the other institutions interviewed, possibly because it presides over the Regional Entrepreneurship Network. On the other hand, there is a noticeable lack of international cooperation furtherance, both public and private, to finance activities that support the creation of businesses in the department.

\section{Acknowledgments}

The authors thank the contributions of Edith Perdomo and Andrés Pulgarín, who worked as research students in the development of this research project, partial requirement to obtain their Master's degree in Administration from the University of Quindío.

\section{References}

Bird, B. 1988. "Implementing entrepreneurial ideas: the case for intention." Academy of Management Review 13(3): $442-453$.

Cámara de Comercio de Armenia y Quindío. 2018. Dinámica empresarial del Quindío 2017. Armenia.

Chang, H. 2006. "La relación entre las instituciones y el desarrollo económico. Problemas teóricos claves." Revista de Economía Institucional 8(14): 125-136.

Congreso de la República de Colombia. 2006. Ley 1014 de 2006.

Edoho, F. 2016. "Entrepreneurship paradigm in the new millennium: A critique of public policy on entrepreneurship." Journal of Entrepreneurship in Emerging Economies 8(2): 279-294.

Díaz, J. 2003. "La creación de empresas en Extremadura.” PhD diss., Universidad de Extremadura.

Eesley, C., Roberts, E., Tian, X. and Yang, D. 2014. "Institutional Flexibility and Entrepreneurship." Stanford Center on Global Poverty and Development 1-59.

Elert, N. and Henrekson, M. 2017. "Entrepreneurship and Institutions: A Bidirectional Relationship." Foundations and Trends in Entrepreneurship 13(3): 191-263.

Fini, R., Grimaldi, R., Marzocchi, G. and Sobrero, M. 2009. "The Foundation of Entrepreneurial Intention.” Conference proceedings in Summer Conference 2009, June 17-19. Frederiksberg, Denmark.

García, A; García, M. and Dias, J. 2018. "The individual's perception of institutional environments and entrepreneurial motivation in developing economies: Evidence from Cape Verde." South African Journal of Economic and Management Sciences 21(1): 1-18.

Jakšić, M., Jakšić, M. 2018. "Inclusive Institutions for Sustainable Economic Development." Journal of Central Banking Theory and Practice 7(1): 5-16.

Kuchař, P. 2016. "Entrepreneurship and institutional change. The case of surrogate motherhood." Journal of Evolutionary Economics 26(2): 349-379.

Liñán, F. and Fayolle, A. 2015. "A systematic literature review on entrepreneurial intentions: citation, thematic analyses, and research agenda." International Entrepreneurship and Management Journal 11(4): 907-933.

Mouselli, S. and Khalifa, B. 2017. "Entrepreneurship in crisis: the determinants of syrian students' entrepreneurial intentions." Business, Management and Education 15(2): 159-173.

Nenzhelele, T. 2014. "Triggering Entrepreneurial Intensions through Experiential Learning in an Open Distance Learning Institution." Mediterranean Journal of Social Sciences 5(16).

North, D. 1981. Structure and Change in Economic History. New York: W.W. Norton.

North, D. 1993a. Instituciones, cambio institucional y desempeño económico. México: Fondo de Cultura Económica. 
North, D. 1993b. "Institutions and Credible Commitment." Journal of Institutional and Theoretical Economics 149(1): 11-23.

North, D. 2000. "La evolución histórica de las formas de gobierno.” Revista de Economía Institucional 2: $133-148$.

Parada, J. 2003. "Economía Institucional Original y Nueva Economía Institucional: semejanzas y diferencias." Revista de Economía Institucional 5(8): 92-115.

Tao, J. 2016. “A Literature Review on Institutional Change and Entrepreneurship." Open Journal of Business and Management 4(4): 630-648.

Thompson, E. 2009. "Individual entrepreneurial intent: Construct clarification and development of an internationally reliable metric." Entrepreneurship Theory and Practice 33(3): 669-694.

Urbano, D., Díaz, J. and Hernández, R. 2007. "Evolución y principios de la teoría económica institucional: Una propuesta de aplicación para el análisis de los factores condicionantes de la creación de empresas." Investigaciones Europeas de Dirección y Economía de la Empresa 13(3): 183-198. 